\title{
Influence of the Central Metal Ion on the Desorption Kinetics of a Porphyrin from the Solution/HOPG Interface
}

\author{
Ashish Bhattarai, Kevin Marchbanks-Owens, Ursula Mazur, K. W. Hipps* \\ Department of Chemistry, Washington State University, Pullman, WA 99164-4630
}

\section{Supplemental Section}

In-situ temperature dependence study of mixture of $\mathrm{CoOEP}$ and $\mathrm{H}_{2} \mathrm{OEP}$ at $70{ }^{\circ} \mathrm{C}$ : Figure S1 shows a sequential STM images for a mixture of $\mathrm{X}_{C}=0.34 \pm 0.03$ at $70{ }^{\circ} \mathrm{C}$ and $\Theta_{C}=0.32 \pm$ 0.04. Out of many images analyzed ( $>7000$ molecules!) at $70{ }^{\circ} \mathrm{C}$, our only indication of molecular exchanges were seen in these images, where only three molecules encircled with yellow and blue have exchanged between the surface and solution.
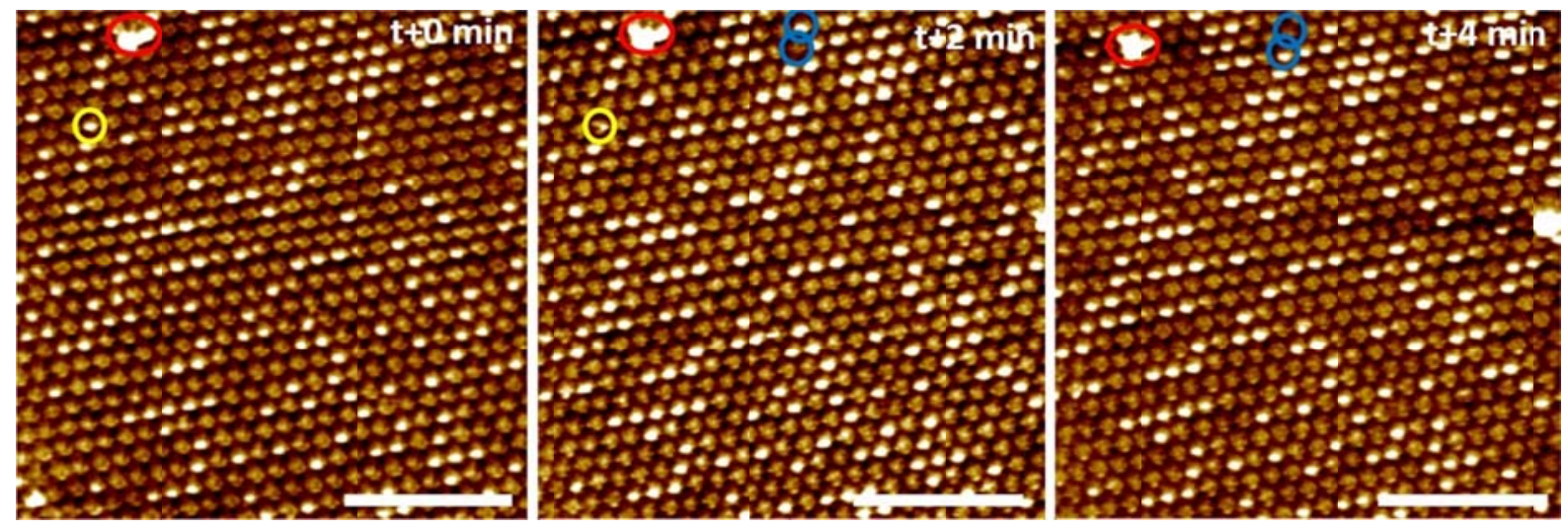

Figure S1. In-situ sequential STM images of $\mathrm{X}_{C}=0.34 \pm 0.03$ at $70{ }^{\circ} \mathrm{C}$ show three molecules exchange between the surface and solution encircled by yellow and blue. The red circle is used as a marker present in all three images. Each image is separated by 2 min apart. Set point conditions: sample bias of $+0.7 \mathrm{~V}$ and current of $20 \mathrm{pA}$. The scale bars shown are $10 \mathrm{~nm}$. 
In-situ temperature dependence study $\mathrm{H}_{2} \mathrm{OEP}$ desorption at $50{ }^{\circ} \mathrm{C}$ : An example of slow desorption rate of OEP $50{ }^{\circ} \mathrm{C}$ is shown in Figure S2. Here, initially a monolayer of $\mathrm{H}_{2} \mathrm{OEP}$ is prepared, then an excess of CoOEP solution is added such that $\mathrm{X}_{C}=0.80$. This is shown in Figure 5. The sample then is heated to $50{ }^{\circ} \mathrm{C}$ and imaged at the same temperature. Figure S2 shows that only $1.6 \%$ of $\mathrm{H}_{2} \mathrm{OEP}$ is desorbed after $5 \mathrm{hr}$ at $50{ }^{\circ} \mathrm{C}$, indicated by the presence of CoOEP.

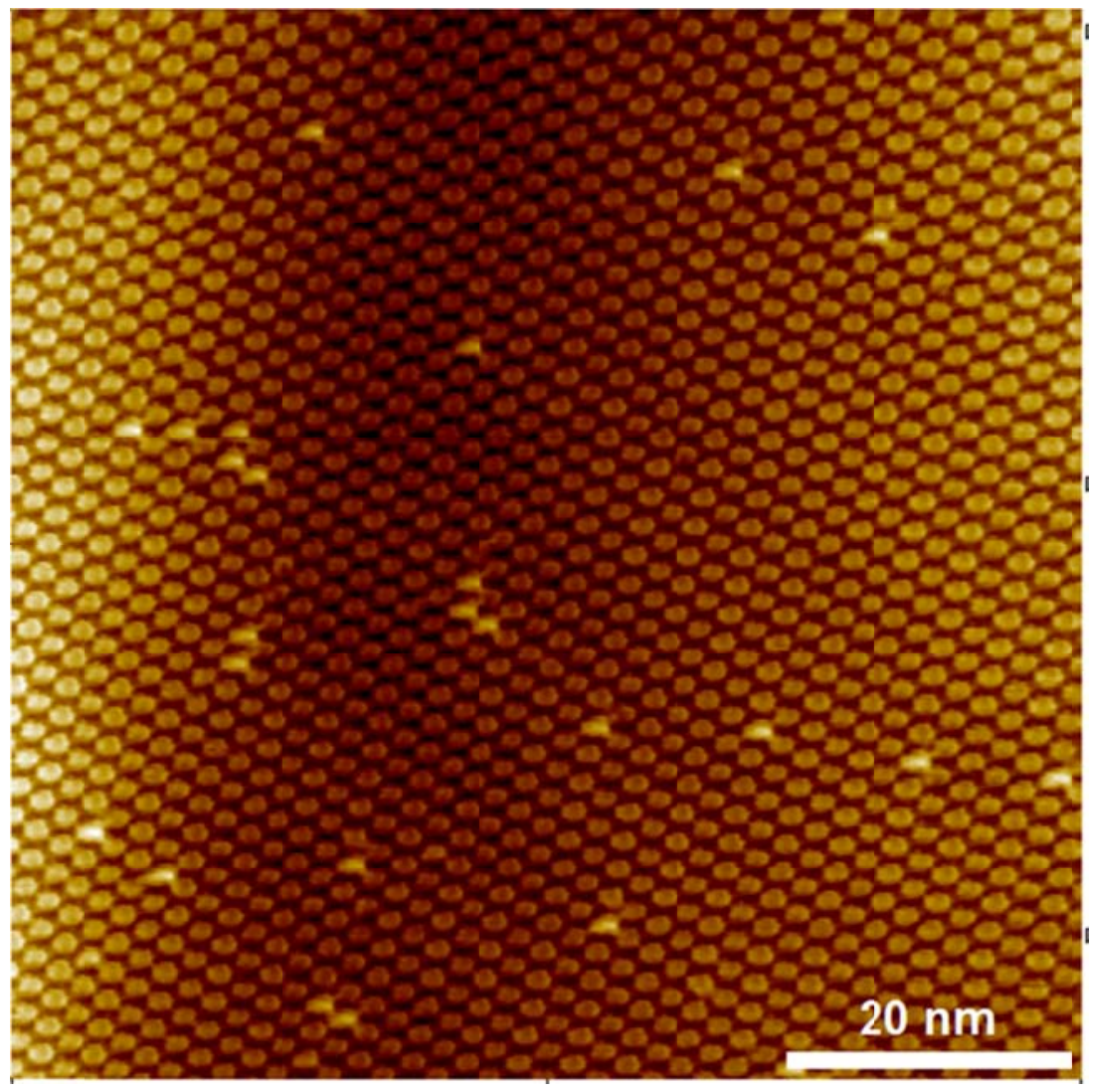

Figure S2: STM image of a monolayer of $\mathrm{H}_{2} \mathrm{OEP}$ that is exposed to $\mathrm{X}_{\mathrm{C}}=0.80$ at $50{ }^{\circ} \mathrm{C}$ after 5 hr.

Tip induced desorption: Tip induced desorption of CoOEP has been previously reported in an earlier study. ${ }^{1}$ Here, we will only focus on desorption for $\mathrm{H}_{2} \mathrm{OEP}$. To study tip induced 
desorption, first a monolayer of $\mathrm{H}_{2} \mathrm{OEP}$ is created, then an excess of CoOEP is added to the solution. Imaging this surface only shows $\mathrm{H}_{2} \mathrm{OEP}$ (figure $\mathrm{S} 1$ (a)). When a pulse of $-4 \mathrm{~V}$ is applied between the tip and the sample, $\mathrm{H}_{2} \mathrm{OEP}$ molecules desorb from the surface and is immediately replaced by the OEP molecules in solution (figure S3 (b), (c), and (d)). Due to the excess CoOEP in solution, the tip induced desorbed section is replenished mostly by CoOEP and can be clearly seen in sequential images in figure $\mathrm{S} 3$ with bright patches of molecules.

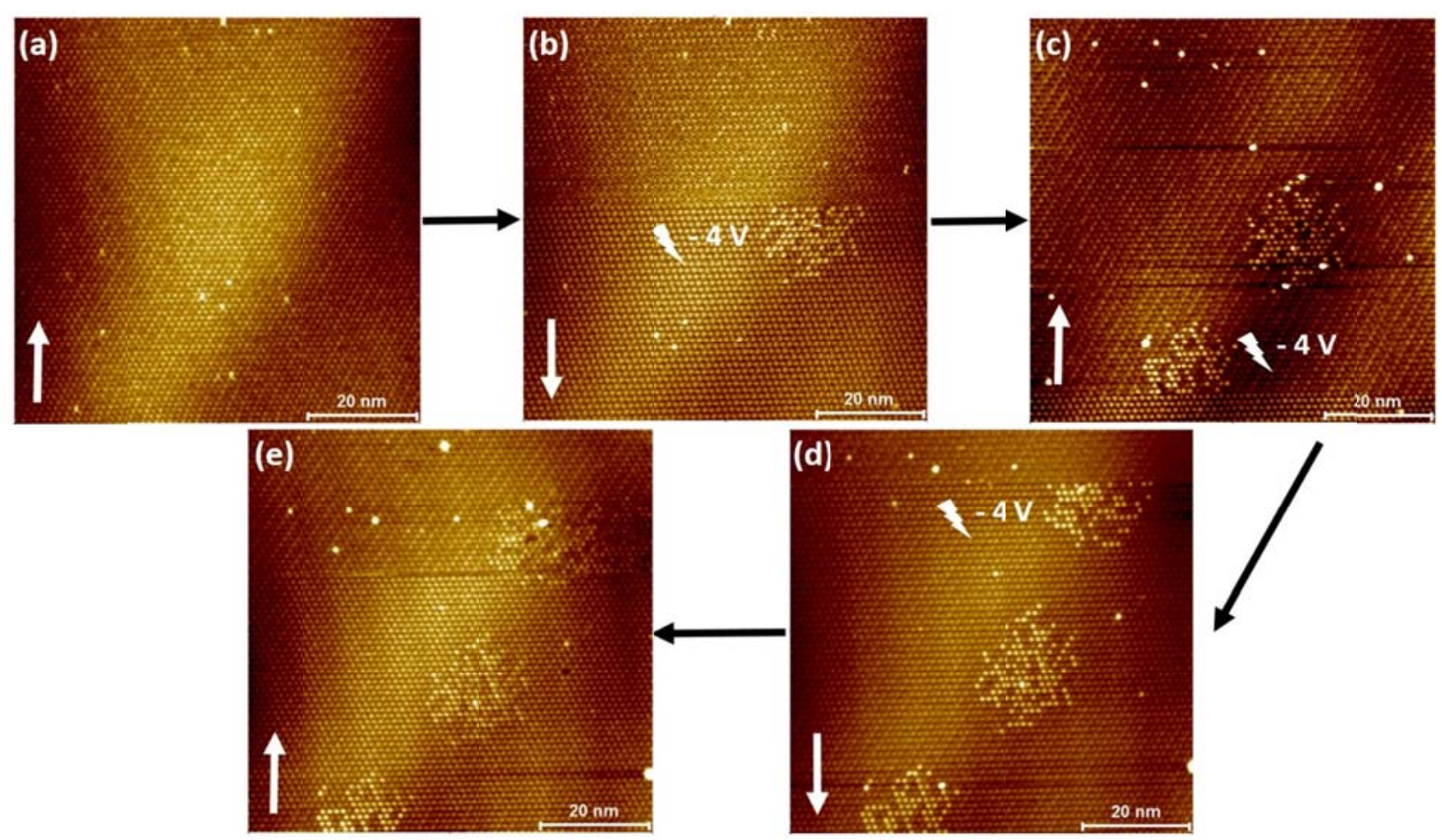

Figure S3: Sequential STM images shows tip induced $\mathrm{H}_{2} \mathrm{OEP}$ desorption from HOPG (a) represents pure $\mathrm{H}_{2} \mathrm{OEP}$ monolayer with excess CoOEP added after monolayer formation (b), (c), and (d) pulse of $-4 \mathrm{~V}$ is applied during scanning in each of the sequential images, and (e) is the final image taken after all three pulses are applied. White arrows show the scanning directions. 
${ }^{1}$ Bhattarai, A.; Mazur, U.; Hipps, K. W. Desorption Kinetics and Activation Energy for Cobalt Octaethylporphyrin from Graphite at the Phenyloctane Solution-Graphite Interface: An STM Study. J. Phys. Chem. C 2015, 119, 9386-9394. 